\title{
CONSIDERATIONS OF RENAL, HEPATIC, AND EXTREMITAL ARTERIOVENOUS DIFFERENCES IN CONCENTRATION OF RADIOMERCURY OF A MERCURIAL DIURETIC ${ }^{1}$
}

\author{
By PERVIS MILNOR,² GEORGE BURCH, THORPE RAY, SAM THREEFOOT AND \\ GERALD BERENSON
}

\author{
(From the Department of Medicine, Tulane University School of Medicine, and Charity Hospital \\ of Louisiana, New Orleans)
}

(Received for publication July 25, 1949)

Mercurial diuretics are employed extensively today in the management of congestive heart failure, but the mechanism by which elimination of electrolytes and water is increased is not thoroughly understood. Furthermore, the metabolism and pharmacodynamics of mercury are only partially known despite the numerous investigations into the diuretic action of mercury. The majority of these studies have been concerned principally with clinical observations on the comparative value of various mercurial preparations, time of onset and quantity of diuresis, efficacy of the preparation in the management of edematous states and toxicity. The anatomic changes in the kidney appearing as a reaction to mercury have been adequately studied, but the physiologic renal changes are not so well understood. The effects of mercurial diuretics on electrolytes, especially chlorine, sodium, and potassium, have received considerable attention, as have the influence of the acidic salts and theophylline in enhancing diuresis. A few investigations have been conducted on the action of mercury on glomerular filtration and tubular reabsorption as well as on the distribution and excretion of mercury. Experiments in animals have demonstrated limited ability of the kidney to remove mercury from the blood when the element is administered in small amounts into the renal artery. Studies of mercurial clearance, only recently possible in man, have not previously been reported.

For purposes of clarifying certain aspects of these problems a mercurial diuretic (Mercuhy-

\footnotetext{
1 Aided by grants from the Life Insurance Medical Research Fund, a War Department Grant No. W-49-007MD-389, and the Mrs. E. J. Caire Fund for Research in Heart Disease.

2 National Institutes of Health Post-doctorate Research Fellow, Department of Medicine, Tulane University School of Medicine, and Charity Hospital of Louisiana at New Orleans.
}

drin $^{8}$ ) labeled with radioactive mercury ${ }^{4}$ has been under study in this laboratory. Observations have been made of the simultaneous concentration-time course of the radiomercury in the serum of the blood from a femoral artery, right renal vein, hepatic vein and an extremital vein and in the urine collected directly from the renal pelvis and urinary bladder. It is the purpose of this presentation to report certain aspects of these data.

\section{MATERIALS AND METHODS}

These studies were conducted on seven subjects from the Charity Hospital; in five, right renal venous catheterization was performed and in two, hepatic venous catheterization (Tables I and II). No subject had received a mercurial diuretic within five days prior to the study. All studies were made at least ten hours postprandially, but no effort was made to regulate diet or intake of water.

In three subjects the urine was collected with ureteral catheters, ${ }^{5}$ by bilateral catheterization in Subject Nos. 1 and 3 and by unilateral catheterization in Subject No. 2; in the other four vesical catheterization was employed. Catheterization of the right renal vein or of a hepatic vein according to the technic of Cournand and Ranges (1) was performed under fluoroscopic control. The position of the catheter was substantiated fluoroscopically at the termination of the study and in three subjects by measuring renal extraction of para-aminohippurate as well. Five per cent dextrose in distilled water was the infusing fluid through the catheter, the quantity admin-

3 The sodium salt of methoxyoximercuripropylsuccinylurea with theophylline, prepared with radiomercury in this laboratory by Messrs. Harold Krahnke, Darwin Kaestner, and Edwin Sprengler through the courtesy of Dr. H. L. Daiell, Director of Research, of Lakeside Laboratories, Milwaukee.

- Radioactive mercury ( $\mathrm{Hg}^{208,205}$ ) was obtained from the Isotopes Division of the Oak Ridge National Laboratories.

5 Cystoscopic examinations were performed by Drs. J. Fishman, H. Bordelon, C. M. Baker, and H. T. King of the Tulane Urologic Service, Charity Hospital of Louisiana. 
TABLE I

Clinical data

\begin{tabular}{|c|c|c|c|c|c|c|}
\hline $\begin{array}{l}\text { Sub- } \\
\text { ject } \\
\text { no. }\end{array}$ & Age & Sex & Wt. & $\begin{array}{l}\text { Blood } \\
\text { BUN }\end{array}$ & Diagnosis & $\begin{array}{l}\text { Treatment } \\
\text { prior to } \\
\text { study }\end{array}$ \\
\hline $\begin{array}{l}\mathbf{1} \\
\mathbf{2} \\
\mathbf{3}\end{array}$ & $\begin{array}{c}\text { yrs. } \\
39 \\
47 \\
51\end{array}$ & $\underset{F}{\mathbf{F}}$ & $\begin{array}{r}\text { lbs. } \\
82 \\
108 \\
148\end{array}$ & $\begin{array}{c}m g .1 \\
100 \mathrm{cc} . \\
\overline{7.7} \\
11.8\end{array}$ & $\begin{array}{l}\text { Gastric neurosis } \\
\text { Hodgkin's disease } \\
\text { Benign essential hyper- }\end{array}$ & $\begin{array}{l}\text { Supportive } \\
\text { Supportive } \\
\text { Salt-poor diet }\end{array}$ \\
\hline 4 & 62 & $\mathbf{M}$ & 191 & 35.0 & $\begin{array}{l}\text { Hypertensive and car- } \\
\text { diovascular heart dis- } \\
\text { ease, mild congestive } \\
\text { failure }\end{array}$ & None \\
\hline 5 & 57 & $\mathbf{M}$ & 119 & 24.6 & $\begin{array}{l}\text { Pleuritis and chronic } \\
\text { pyelonephritis } \\
\text { (Left nephrectomy } \\
1943 \text { for chronic } \\
\text { pyelonephritis) }\end{array}$ & Supportive \\
\hline $\begin{array}{l}6 \\
7\end{array}$ & $\begin{array}{l}37 \\
48\end{array}$ & $\frac{\mathbf{M}}{\mathbf{F}}$ & $\begin{array}{r}144 \\
97\end{array}$ & 66 & $\begin{array}{l}\text { Amebiasis } \\
\text { Hypertensive and car- } \\
\text { diovascular heart dis- } \\
\text { ease and anemic heart } \\
\text { disease, with severe } \\
\text { congestive failure and } \\
\text { uremia }\end{array}$ & $\begin{array}{l}\text { Supportive } \\
\text { Digitalis; } \\
\text { ammonium } \\
\text { chloride; } \\
\text { salt-poor } \\
\text { diet }\end{array}$ \\
\hline
\end{tabular}

istered during the study varying from 500 to $1800 \mathrm{cc}$. (Table II). Collections of arterial blood were made from the left femoral artery. A measured volume (See Table II) of Mercuhydrin labeled with $\mathrm{Hg}{ }^{203,}{ }^{205}$, with an activity of $8,000,000$ to $2,500,000$ counts per minute per cc., was then injected into an extremital vein over an interval of 15 to 40 seconds.

Samples of $4 \mathrm{cc}$. of blood were collected as nearly. simultaneously as possible from the right renal vein or hepatic vein, the femoral artery, and a peripheral vein other than that used for the injection. Because the capacity of the venous catheter was $1.2 \mathrm{cc} ., 2 \mathrm{cc}$. of renal or hepatic venous blood were withdrawn and discarded before each sample was obtained. Separate samples of urine were collected from the catheters as nearly coincidentally as possible with the time of withdrawal of the blood samples.' Ordinarily, these were obtained at one-minute intervals for five minutes, threeminute intervals for the next 10 minutes, and at gradually increasing intervals of five, 10,15 , or 30 minutes thereafter as the study progressed. Duration of the studies varied from 60 to 240 minutes.
Triplicate determinations of radioactivity of each sample were made with a mica window Geiger-Müller counter. The concentration of $\mathrm{Hg}^{203,205}$ in all samples was expressed, after the usual corrections, as counts per minute per cc. of biologic fluid and was corrected to a standard dose of $10,000,000$ counts per minute. The error for counting of the samples of serum was less than 5 per cent, whereas that for the urine was considerably greater but was always of a negative order. Subsequent studies and reevaluation of the procedure for the urine have shown that volatilization of mercury from, and deliquescence of, urinary slides prepared by heating in an oven for 20 minutes at $80^{\circ} \mathrm{C}$. may cause a loss of radioactivity varying from 10 to 50 per cent. Mean error of these determinations is 20 per cent. Despite these errors, certain observations concerning urinary excretion of mercury are considered worthy of presentation.

In order to test for possible reabsorption of mercury from the urinary bladder, 2 cc. of the radioactive mercurial diuretic were injected into a patient's bladder. This resulted in no detectable increase in the radioactivity of the blood.

\section{RESULTS}

Results are summarized in Figures 1 through 11 ; certain aspects deserve discussion.

\section{Blood}

(a) Concentration-time course of radiomercury. Variations in concentration with time of the femoral arterial serum, renal or hepatic venous serum and extremital venous serum collected simultaneously are shown in Figures 1, 2, and 3. These figures exhibit a pattern which was essentially the same for all the sera. Since these regressions were similar to those previously reported (2), except for differences due to the relatively slow rate of injection of the material, they will not be discussed here in detail. Although

TABLE II

Experimental data

\begin{tabular}{|c|c|c|c|c|c|c|}
\hline $\begin{array}{c}\text { Subject } \\
\text { no. }\end{array}$ & Pre-study medication & $\begin{array}{c}\text { Type } \\
\text { venous } \\
\text { catheterization }\end{array}$ & $\begin{array}{l}\text { Type of } \\
\text { urinary } \\
\text { collections }\end{array}$ & $\begin{array}{c}\text { Dose of } \\
\text { mercurial } \\
\text { diuretic }\end{array}$ & $\begin{array}{l}\text { Dose of } \\
\text { radio- } \\
\text { mercury }\end{array}$ & $\begin{array}{l}\text { Volume } \\
\text { fluid } \\
\text { infused }\end{array}$ \\
\hline 1 & $\begin{array}{l}\text { Morphine sulphate, gr. 1/6; } \\
\text { atropine, gr. } 1 / 150\end{array}$ & Renal & Pelvic & $\begin{array}{l}c c . \\
1.5\end{array}$ & $\begin{array}{c}C P M \\
13,103,493\end{array}$ & $\begin{array}{c}c c . \\
1,200\end{array}$ \\
\hline 2 & $\begin{array}{l}\text { Morphine sulphate, gr. 1/6; } \\
\text { atropine, gr. 1/150 }\end{array}$ & Renal & Pelvic & 2 & $14,290,080$ & 600 \\
\hline 3 & $\begin{array}{l}\text { Morphine sulphate, gr. 1/6; } \\
\text { atropine, gr. } 1 / 150\end{array}$ & Renal & Pelvic & 2 & $13,524,540$ & 1,000 \\
\hline 4 & $\begin{array}{l}\text { Morphine sulphate, gr. 1/6; } \\
\text { atropine, gr. } 1 / 150\end{array}$ & Renal & Pelvic & 3 & $11,092,674$ & 1,800 \\
\hline $\begin{array}{l}5 \\
6 \\
7\end{array}$ & $\begin{array}{l}\text { Seconal, 0.1 gm. } \\
\text { Seconal, 0.1 gm. } \\
\text { Seconal, } 0.1 \text { gm. }\end{array}$ & $\begin{array}{l}\text { Renal } \\
\text { Hepatic } \\
\text { Hepatic }\end{array}$ & $\begin{array}{l}\text { Vesical } \\
\text { Vesical } \\
\text { Vesical }\end{array}$ & $\begin{array}{l}2 \\
3 \\
3\end{array}$ & $\begin{array}{r}11,992,460 \\
9,021,000 \\
8,435,700\end{array}$ & $\begin{array}{r}1,500 \\
700 \\
500\end{array}$ \\
\hline
\end{tabular}


the curves of blood regression were similar in general form, the slopes of the curves of renal venous sera were steeper in their first portions and shallower in their terminal portions than those of the arterial (Figure 1). A significant difference observed for the various subjects studied was partially due to the rate of injection.

(b) Sera of arterial and renal venous blood. It is evident from Figure 1 that there were consist-

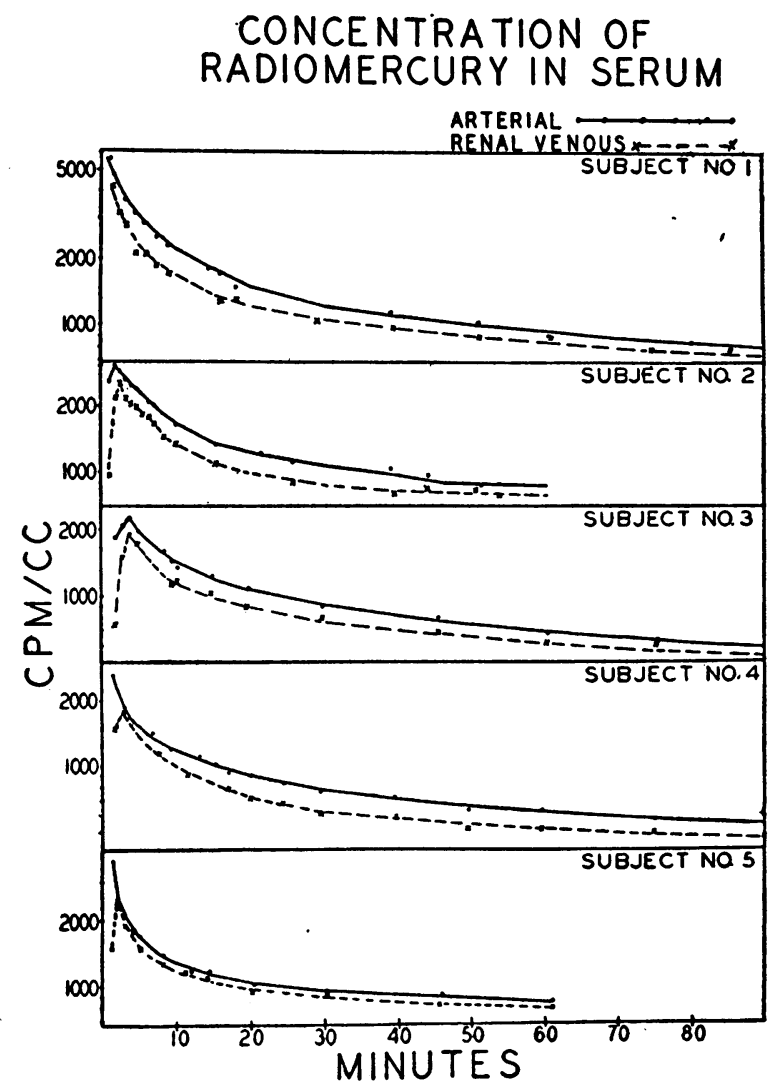

Fig. 1. A Comparison of the Variations with Time of the Concentrations of Radiomercury in the Serum of Femoral Arterial Blood and Right Renal Venous Blood of Five Subjects

ently higher levels of concentration of radiomercury in the serum of the arterial blood than in that of the renal venous blood throughout the period of study. In general the absolute difference was greatest during the initial two to three minutes and variable during the first 10 minutes, after which it declined slowly until termination of the study. The time course of the percentage difference $\left(\frac{A-R}{A} \times 100\right)$ is shown in Figure $4 \mathrm{~A}$.

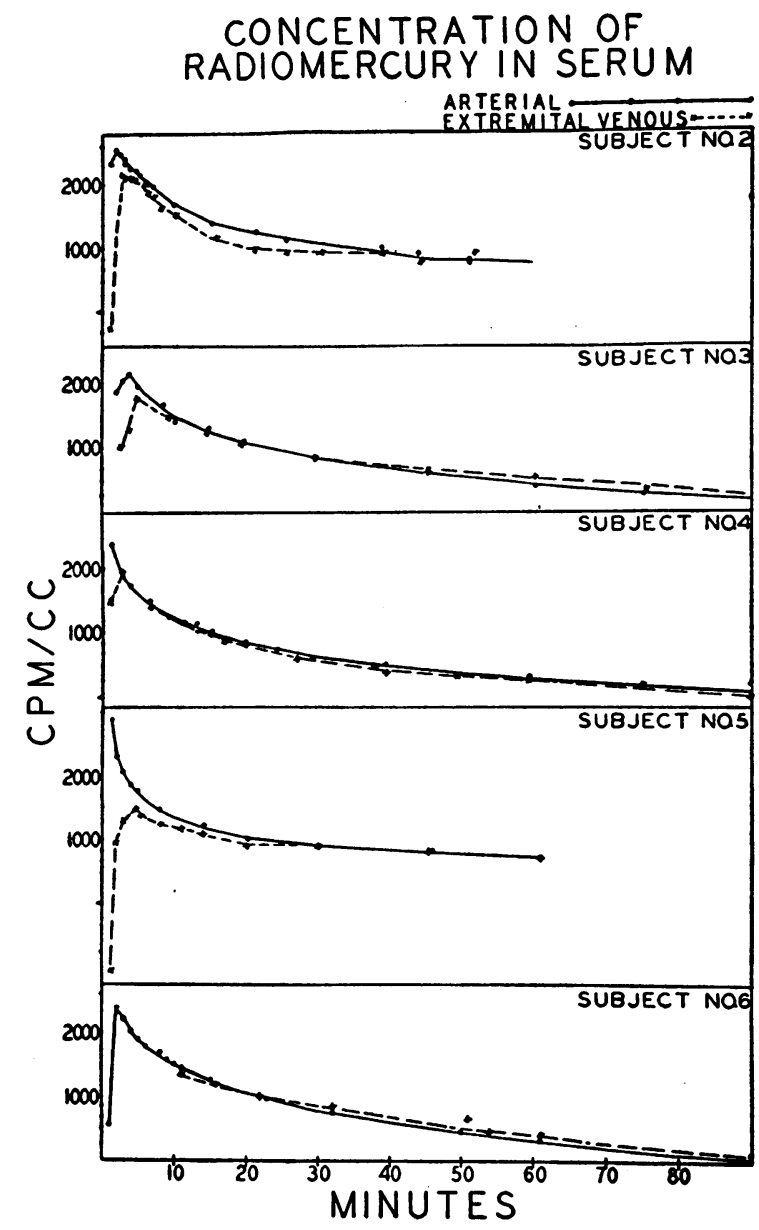

Fig. 2. A Comparison of the Variations with Time of the Concentrations of Radiomercury in the Serum of Femoral Arterial Blood aNd Blood from a Peripheral Vein of Five Subjects

CONCENTRATION OF RADIOMERCURY IN SERUM

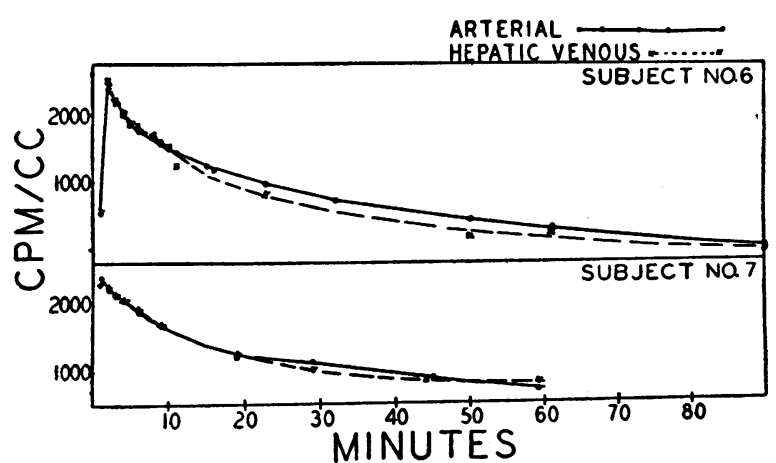

Fig. 3. A Comparison of the Variations with Time of the Concentration of Radiomercury in the Serum of Femoral Arterial Blood and Hepatic Venous Blood of Two Subjects 
(c) Serum of arterial and extremital venous blood. Differences in concentration of radiomercury between the serum of arterial blood and that of extremital venous blood tended to be nonexistent after the initial 10 to 20 minutes. During the first five minutes differences were greater than either arterial-renal or arterial-hepatic differences (Figures 2 and 4B). Although not shown together, after five minutes renal venous concentration was consistently lower than extremital venous concentration, except in the case of Subject No. 5 with one kidney (Figures 2 and $4 \mathrm{~A}$ and B).

(d) Sera of arterial and hepatic venous blood. After the first 10 minutes, concentration of arterial radiomercury was consistently higher than that of hepatic venous radiomercury in one normal subject; no consistent difference was observed between the two vessels in a patient with severe chronic congestive heart failure. Significant arterial and hepatic venous differences did not exist during the initial 10 minutes of the study in either subject (Figures 3 and $4 \mathrm{C}$ ).

(e) Percentage extraction. The percentage of radiomercury extracted from the arterial blood is indicated in Figure 4.

$$
E=\frac{A-R}{A} \times 100,
$$

where $E=$ percentage of arterial mercury extracted,

$A=$ concentration in arterial blood serum, and

$R=$ concentration in renal venous blood serum.

These curves (Figure 4) were derived from the values shown in Figures 1, 2, and 3, which were based on the actual observed values of radiomercurial concentration. Renal percentage extraction tended to be greatest initially, although wide variations were noted during the first 10 to 20 minutes. Thereafter it showed a slow decline

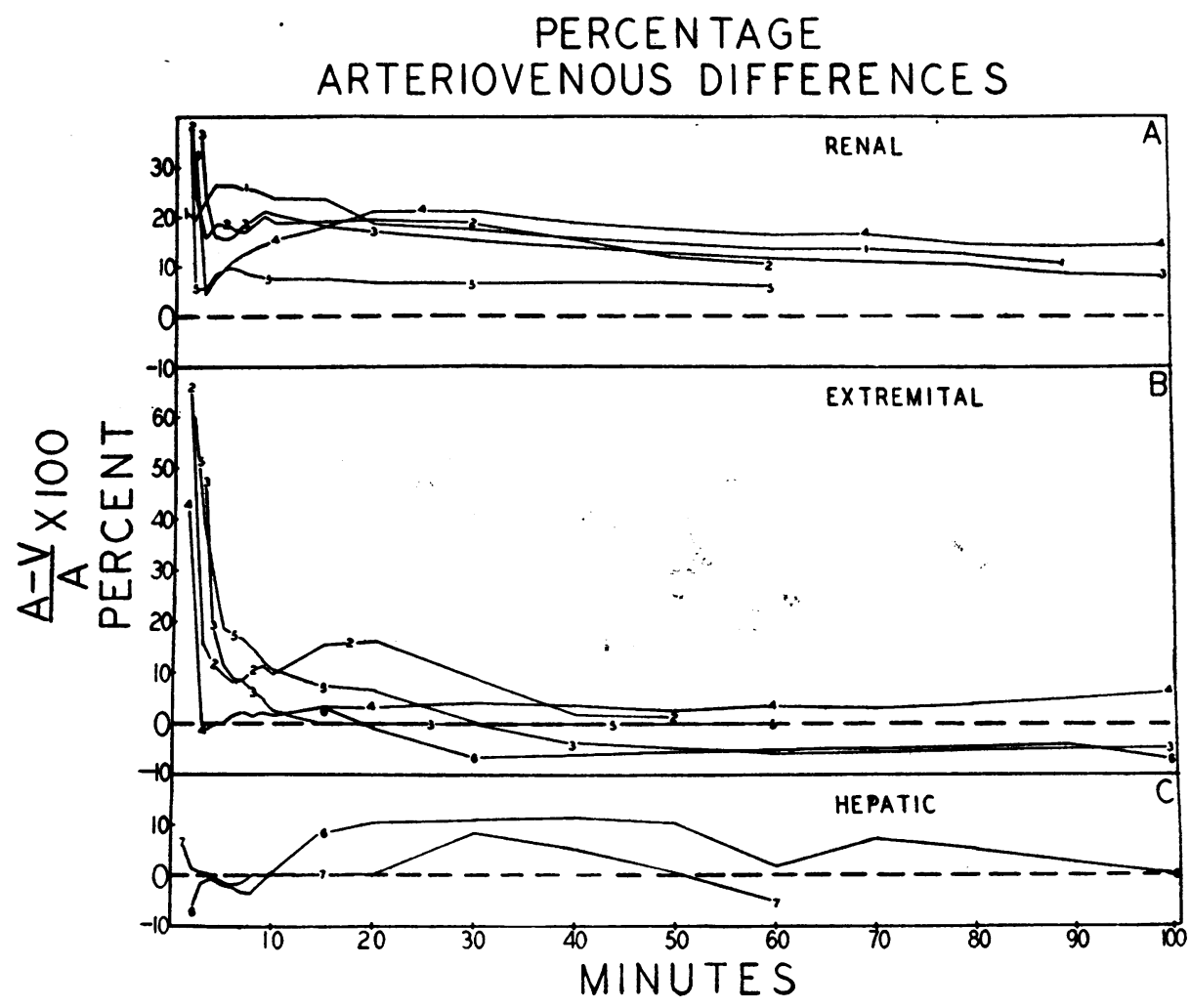

Fig. 4. A Comparison of the Variations with Time of Renal, Extremital, and Hepatic Percentage Arteriovenous Differences in Concentration of RadiomerCURY 
in all cases. Subject No. 5, with only a right kidney, showed about one-half the percentage difference observed for the same kidney of the other four subjects (Figures 1, 2, 3, and 4). Tissues of the extremities exhibited a large percentage difference for mercury during the early periods of the experiments but no significant difference thereafter (Figures 2 and 4B). For normal Subject No. 6 there was a definite hepatic ex- traction, whereas for Subject No. 7, with severe chronic congestive heart failure, no significant hepatic extraction was observed (Figures 3 and 4C).

Because of continuous changes it was not possible to determine precise averages of rates of extraction of radiomercury for the kidneys and liver. However, at 30 minutes the renal rate of extraction tended to be about 10 to 20 per cent, the

\section{URINARY CONCENTRATION OF RADIOMERCURY AND RATE OF VOLUME FLOW}

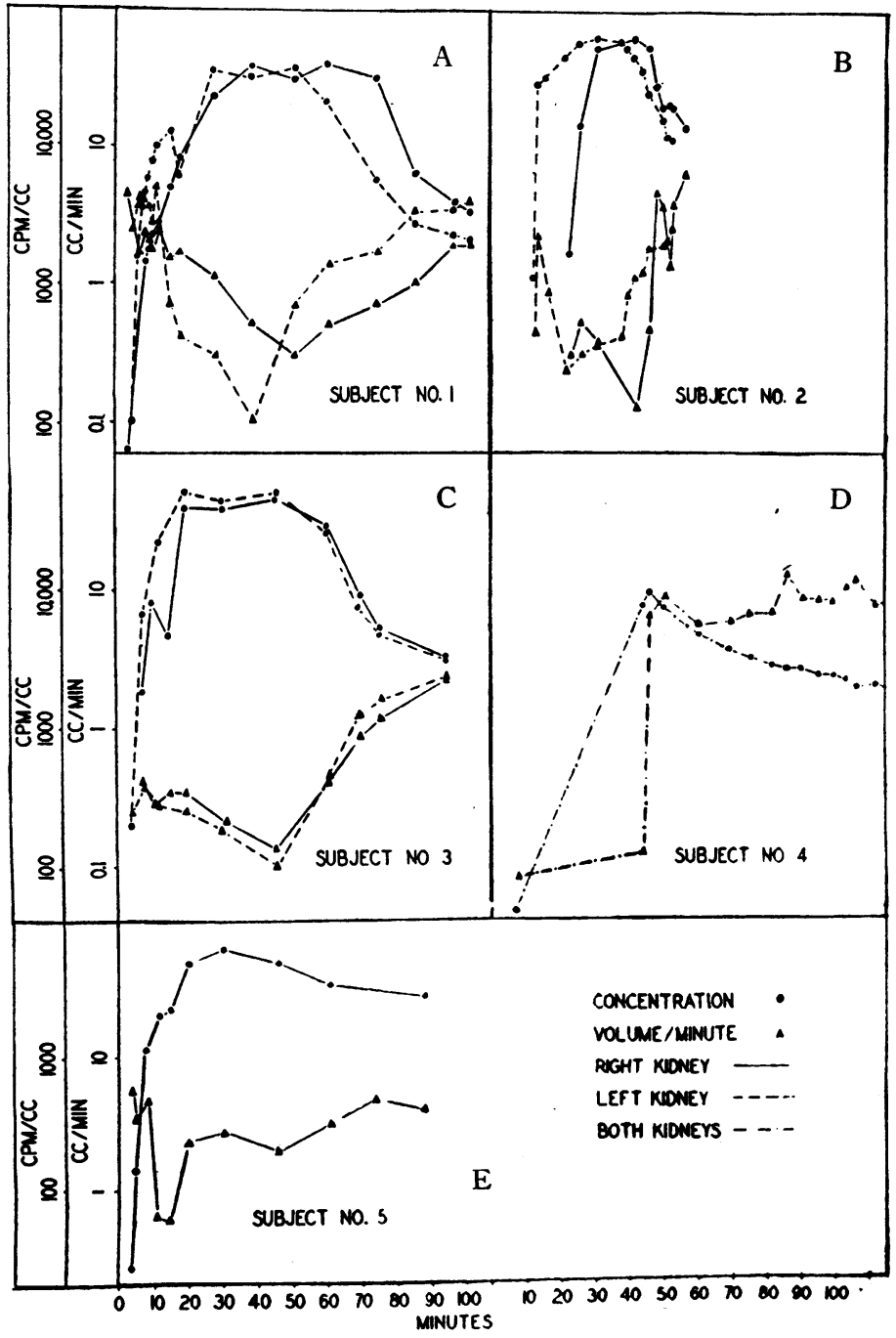

Fig. 5. A Comparison of the Variations with Time of the URINARY CoNCENTRation OF RADIOMERCURY AND OF THE URINARY Rate of Volume Flow of Five Subjects

Functions of the kidneys of the same subject are compared for Subject Nos. 1, 2, and 3. 
hepatic 5 to 10 per cent in the normal subject, and the tissues of the extremities zero.

\section{Urine}

Only the five subjects in whom renal venous catheterization was performed are included in the discussions concerning the urine.

(a) Concentration-time course of radiomercury. Variations in concentration with time of radiomercury in the urine of these subjects are shown in Figure 5. The time of appearance of radiomercury in the urine was three and one-half to five minutes in three subjects (Nos. $1,3,5$ ); in the other two (Nos. 2 and 4) temporary obstruction to flow through the catheter invalidated these measurements. In three subjects (Nos. 1, 2, 3) concentration of the radiomercury rose rapidly, reaching a maximum level in 20 to 30 minutes, and remained at this high level for 30 to $60 \mathrm{~min}$ utes. Differences in patterns for Subject Nos. 4 and 5 may be due to temporary obstruction in the former and to a single kidney in the latter. The rate of decline in concentration varied, being fairly rapid in Subject Nos. 1, 2, 3, and 4, with both kidneys, and relatively slow in Subject No. 5 with a single kidney. The illustrations show a

TIME COURSE OF RENAL CLEARANCE AND RATE OF EXCRETION OF HG ${ }^{203-205}$

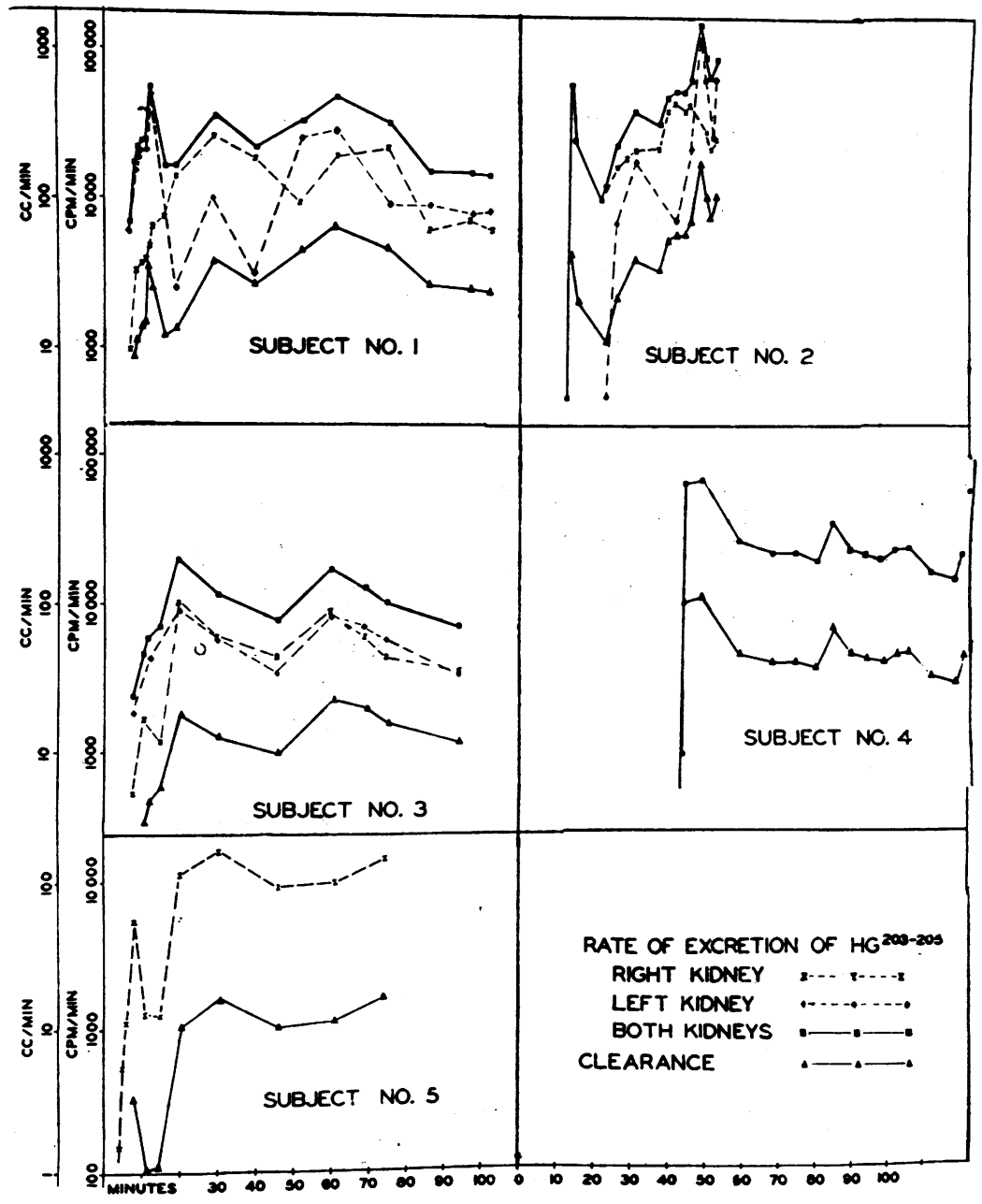

Fig. 6. A Comparison of the Variations with Time of the Urinary Rate of Excretion of Radiomercury and of the Renal Clearance of Radiomercury of Five SubJects 


\section{RELATIONSHIP OF. ARTERIAL CONCENTRATION TO RENAL $A-V$ DIFFERENCE}

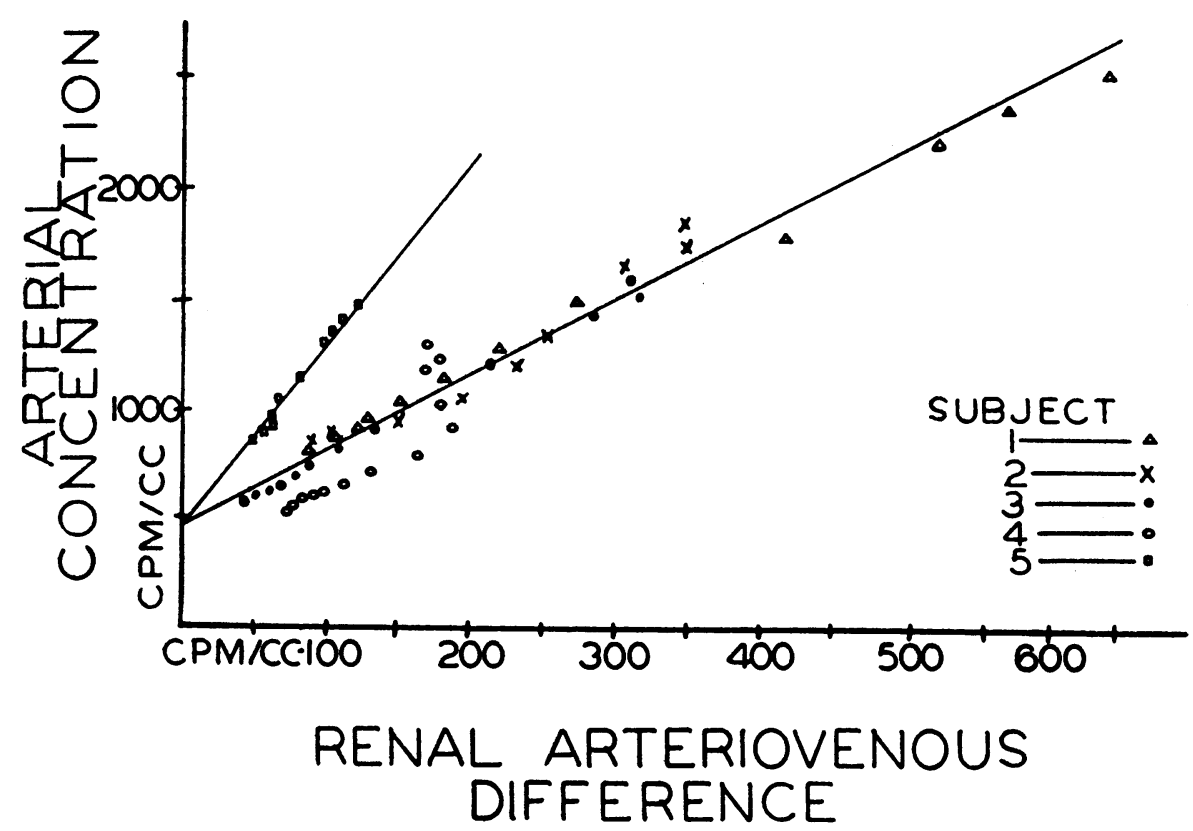

Fig. 7. Correlation of Arterial Concentration with Renal Arteriovenous Differences in Concentration of Radiomercury

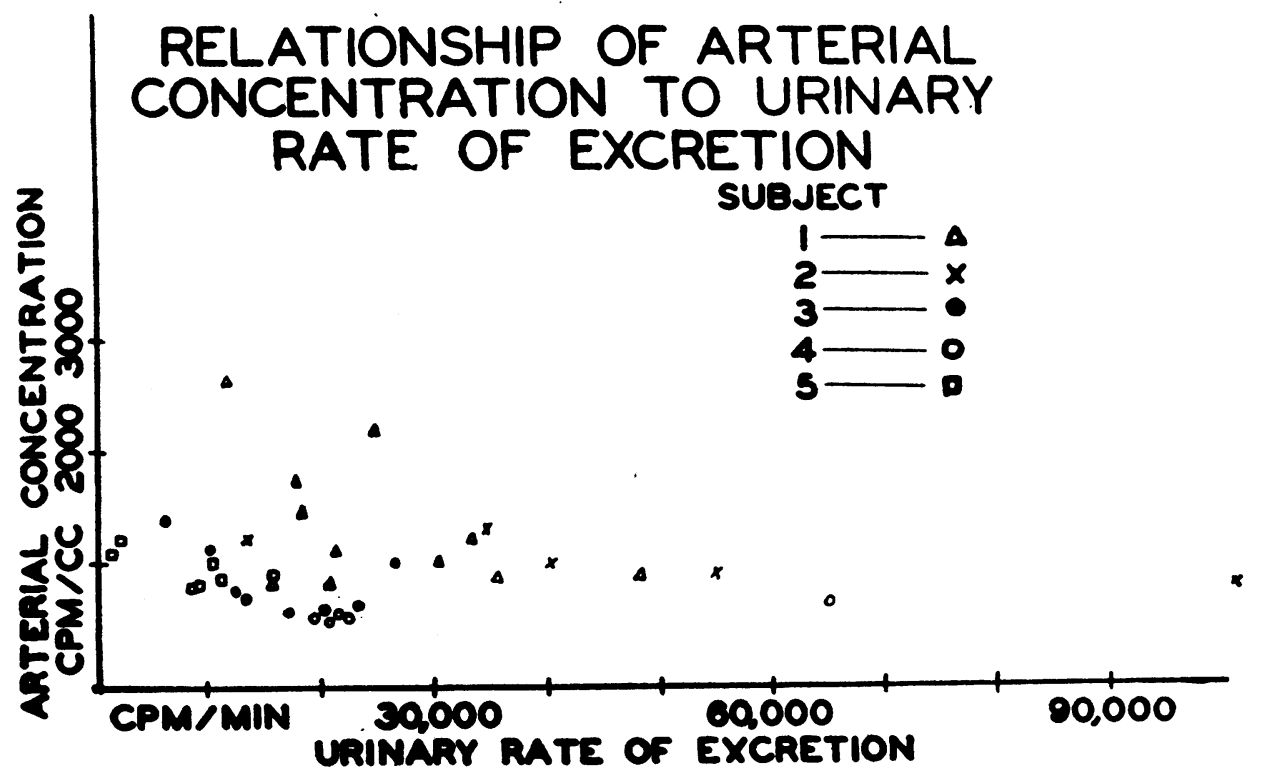

Fig. 8. Correlation of Arterial Concentration with Urinary Ratio of EXCRETION OF RADIOMERCURY 
remarkably consistent concordant variation in concentration of radiomercury for the right and left kidneys in the three patients in whom ureteral catheterization allowed separate but simultaneous observations. The configurations of the curves were similar quantitatively as well as qualitatively. There was a lag of 20 minutes or more between the peak concentration of radiomercury in the serum and the peak concentration in the urine (Figures 1 and 5). Because of an obstruction to flow through the catheter in Subject No. 4, urine was not collected between the seventh and 44th minutes of the experiment, so that the early portion of the urinary concentration-time course was disturbed.

(b) Volume of urine. In the four subjects in whom early urinary samples were obtained there was a decided decline in the rate of urinary flow as the concentration of radiomercury increased (Figure 5A, B, C, E). In the three subjects in whom pelvic urine was collected from each kidney and was studied separately, the volume-time course of urinary flow varied concordantly (Figure 5A, $\mathrm{B}, \mathrm{C})$.

(c) Rate of excretion of radiomercury. The total per minute excretion (UV or concentration times rate of volume flow per minute) increased rapidly during the first 10 to 30 minutes in Subject Nos. $1,2,3$, and 5 to reach a plateau which was relatively well maintained for the remainder of the study (Figure 6). Since no urine was obtained from Subject No. 4 between the seventh and 44th minutes, the accumulated output yielded a high excretion in the first few specimens.

(d) Radiomercurial clearance. Figure 6 illustrates the radiomercurial clearance,

$$
C=\frac{U V}{A},
$$

where $C=$ cubic centimeters of blood cleared per minute,

$U=$ concentration of radiomercury (counts per minute per cc.) in the urine,

$V=$ rate of urinary flow in cc. per minute, and

$A=$ concentration in the serum of the arterial blood.

Rates of clearance varied considerably from subject to subject and with time in the same subject. In general, however, the rate of clearance was low in the early minutes of the experiments, then rose rapidly after about 10 minutes, i.e., tended to follow the pattern of excretion. Rates of clearance

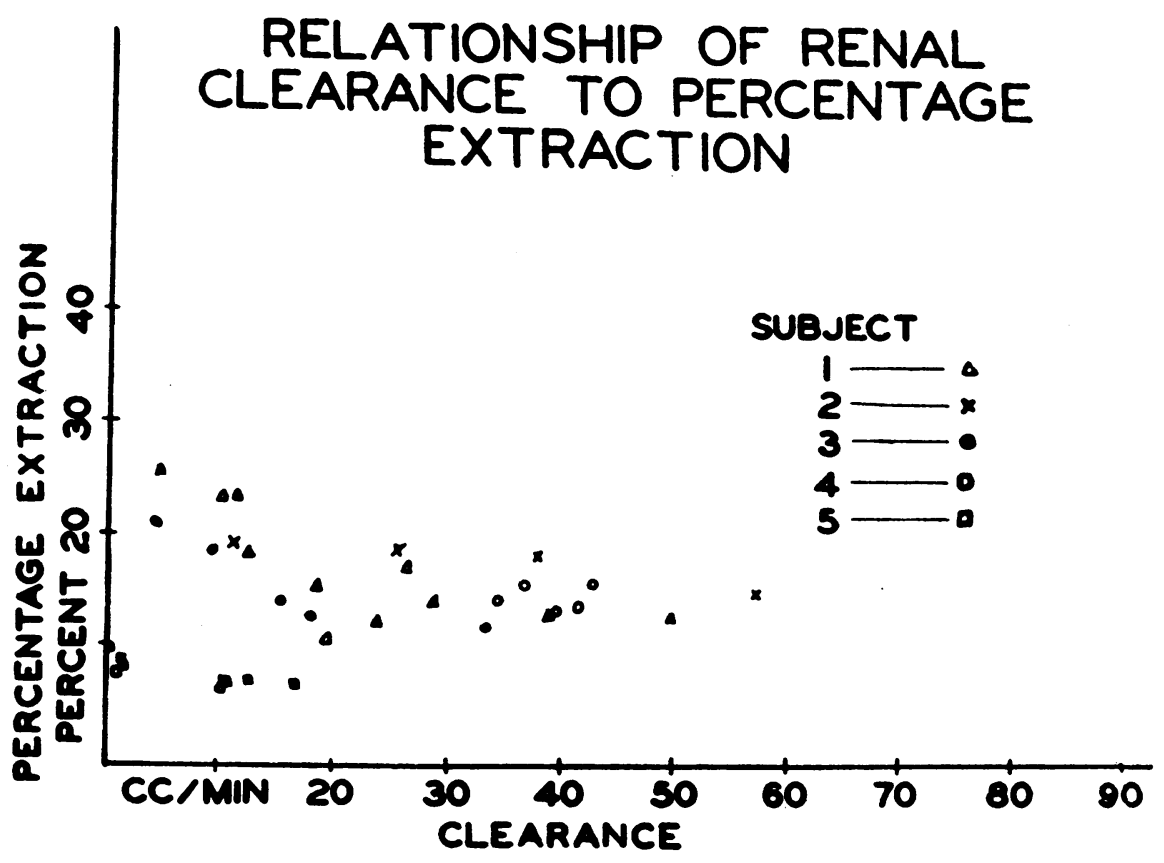

Fig. 9. Correlation of Renal Clearance with Renal Percentage EXTRACTION OF RADIOMERCURY 
by the right and left kidneys in the three subjects in whom separate pelvic urinary samples were collected tended to vary concordantly (Figure 6).

\section{Correlation of Data}

(a) Relationship of concentration of radiomercury in arterial serum and renal arteriovenous differences. This relationship is illustrated by Figure 7. The rate of extraction tended to vary directly with the concentration of radiomercury in the serum of the arterial blood after seven minutes. The slopes indicating their relationship for Subject Nos. 1, 2, and 3 were similar (3.5), with that for Subject No. 4 at a slightly lower level. Subject No. 5 had a slower rate of extraction for relatively high concentrations in the serum, i.e., a steeper slope (8.3).

(b) Relationship of the rate of urinary excretion of radiomercury to the radiomercurial concentration of arterial serum. Figure 8 demonstrates this relationship. The rate of excretion of radiomercury per minute showed little or no correlation with the concentration of the radioelement in the blood. The most rapid rates of excretion were observed when the serum concentrations were at the lowest levels during the period of study.

(c) Relationship of radiomercurial clearance and radiomercurial percentage extraction. In Figure 9 is shown the relationship of radiomercurial clearance to $\left(C\right.$ to $E$, or $\left.\frac{A-R}{A} \times 100\right)$. The clearance rate varied independently of the percentage extraction. As the study progressed, the latter fraction declined slowly, whereas the clearance rate increased. Therefore, during periods of essentially the same or even lower rates of extraction, rates of clearance were high or increased (Figure 9). It is evident that the same type of relationship exists for the percentage extraction and rate of excretion of radiomercury.

(d) General correlations of data. Limitation of space does not permit a presentation of a composite illustration for each subject; one such illustration (Figure 10) is presented to show the relationship of the various data. Although the figure is complex in appearance, careful study permits an evaluation of quantitative and qualitative relationships from many points of view. A discussion of the data in this figure is unnecessary.

COMPOSITE DATA ON SUBJECT NO. 3

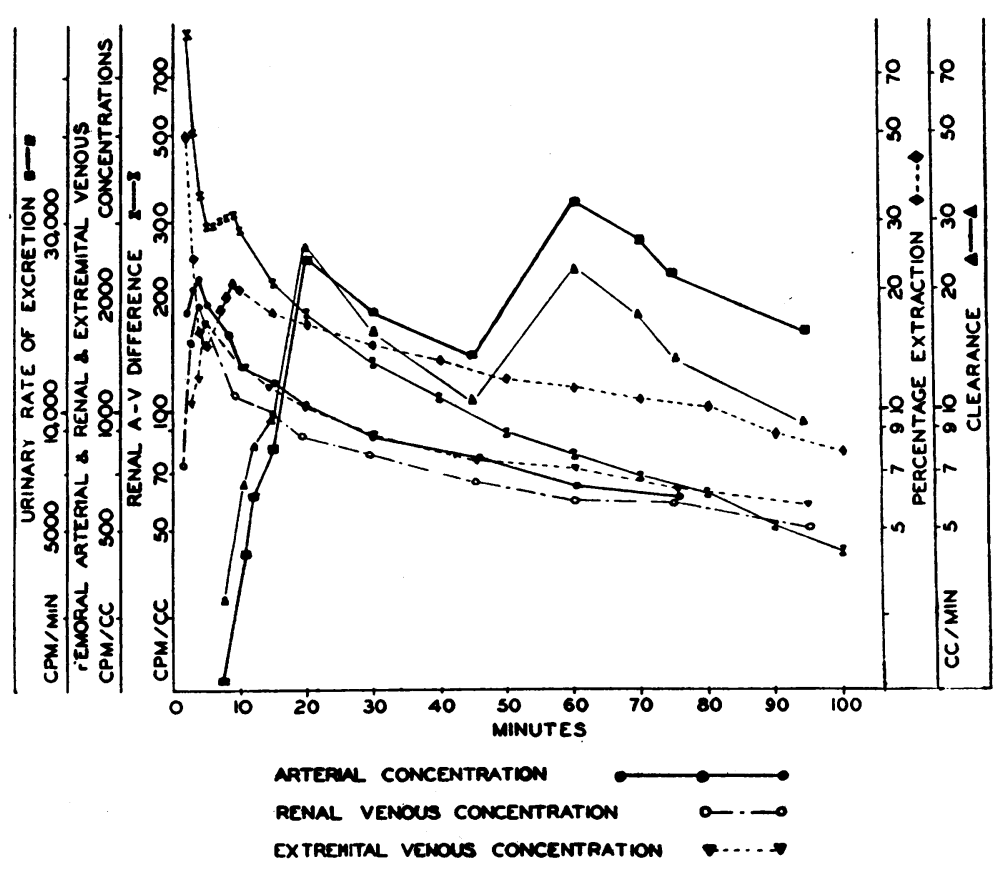

Fig. 10. A Composite Graph for Comparison of Certain of the More Important Measurements Made on One of the Subjects 


\section{DISCUSSION}

The foregoing parameters are not intended as renal function tests but were devised to investigate the method by which mercury is cleared from the blood and excreted by the kidneys. In these studies it was not possible to apply the same interpretations to clearance and extraction of radiomercury as are applied to clearance and extraction of para-aminohippurate or to clearance of inulin.

Although the mercury was introduced as part of a complex organic compound, Mercuhydrin, only the mercury itself was traced. There are no data to show that the Mercuhydrin molecule was ever under observation, although at certain periods of the study it may have been. The chemical complexes of the mercury must have varied considerably during the course of the studies. Although only the radioactive mercury was traced and not any specific chemical form thereof, the experiments revealed some aspects of distribution and behavior of the mercury of the diuretic after intravenous administration. The behavior of the radiomercury as observed is identical with that of the nonradioactive mercury of the diuretic and therefore can be accepted as characteristic of all the mercury of the mercurial diuretic.

Unavoidable limitations in experiments of this kind necessitated some restrictions in the interpretations and applications of the results and therefore prevented certain analyses. One limitation is that introduced by the time required for circulation through the organ studied, i.e., kidney, liver, or extremity. Inspection of Figure 1 reveals how the differences between concentrations of arterial and venous sera could vary if the time relationship between simultaneous points on the curves of arterial and renal regression were varied only 10 or 20 seconds. Fortunately, an error from such a factor was possible only during the first five to 10 minutes of this study, because the slopes of the curves of regression were too shallow after this time to introduce a significant error.

Another limitation, always present in any such study in which urinary clearance is correlated with renal extraction, by means of renal arteriovenous differences, is that due to a lag in time of appearance of urine at the exit of the catheter after its production from a given glomerular filtrate. The interval of time required for the radiomercury to appear in the urine at the end of the ureteral catheter after intravenous injection of the tracer varies from three and one-half to five minutes. Causes for this delay can only be conjectural. This time lag, however, renders it highly improbable that the extraction value can be exactly superimposed in time upon the clearance value for any particular mass of blood. This type of error applies to other substances, such as inulin and diodrast, as well as to tracer materials.

During this study it was assumed that femoral arterial serum had the same concentration of radiomercury as renal arterial serum. There is no reason to believe that differences in concentration between renal and femoral arterial sera after one to five minutes would be sufficiently large to be detected by these methods. Such an assumption is subject to error during the first one to five minutes of each experiment. The early arteriovenous hepatic, renal and extremital differences in concentration of radiomercury may have been due in part to the influence of inadequate mixing. For instance, mixing must be responsible for a considerable part of the large renal arteriovenous and large extremital arteriovenous differences observed during ascension of the curve of the concentration-time course of Subject Nos. 2, 3, 4, and 5. Studies of other observers (3) suggest that mixing introduces no significant error after one to two minutes. The degree of differences in arteriovenous concentrations of the tracer and the smoothness of the curves preclude any important errors due to mixing after the initial five minutes or even less in these experiments. Furthermore, it will be indicated later that the differences observed among these various venous sera are at least partially due to other factors.

Variations between the renal venous curves of regression and the arterial curves of regression are of assistance in the understanding of the handling of mercury by the kidneys. The more rapid renal venous rates of regression observed during the first 10 minutes, and the less rapid renal venous rates after 20 minutes, as compared with the arterial rates of regression, suggest the influence of local factors upon the rate of removal of the tracer from the latter. This must be at- 
tributable in part to changes in ratio of extraction of mercury from the blood as it circulates through the kidney, the details of which are shown in Figure 4. It cannot be explained by the error due to time required for circulation through the kidney because the latter does not influence the slopes of the curves, i.e., the rates of regression.

These differences in arteriovenous concentration observed for the kidneys, liver and upper extremity contribute to a better understanding of the mechanisms responsible for the concentration-time course in the blood of the tracers previously reported for man (2). For example, Figure 11 illustrates the concentration-time course of radiomercury in the serum of femoral arterial blood of Subject No. 1 analyzed into three main components of regression. Also included is a simultaneously measured concentration-time course of the tracer for serum of renal venous blood, the time course of the difference in concentration between arterial and renal venous sera and the time course of the percentage renal extraction. Such analyses were obtained for each subject.

Figure 11 shows that renal percentage extraction was relatively low during the period of time of most rapid arterial regression, which would indicate strongly that mixing and factors other than renal extraction are most responsible for the initial regression in arterial or venous concentration. However, since there was a definite extraction by the renal tissue in progress at this time, it was also responsible in part for the regression in concentration. In order for phenomena of extraction to be partially responsible for this most rapid of the three rates of regression, they must likewise be rapid and must be functioning during the first five or six minutes of the experiment.

On the other hand, in the curve of percentage extraction with time, shown at the bottom of

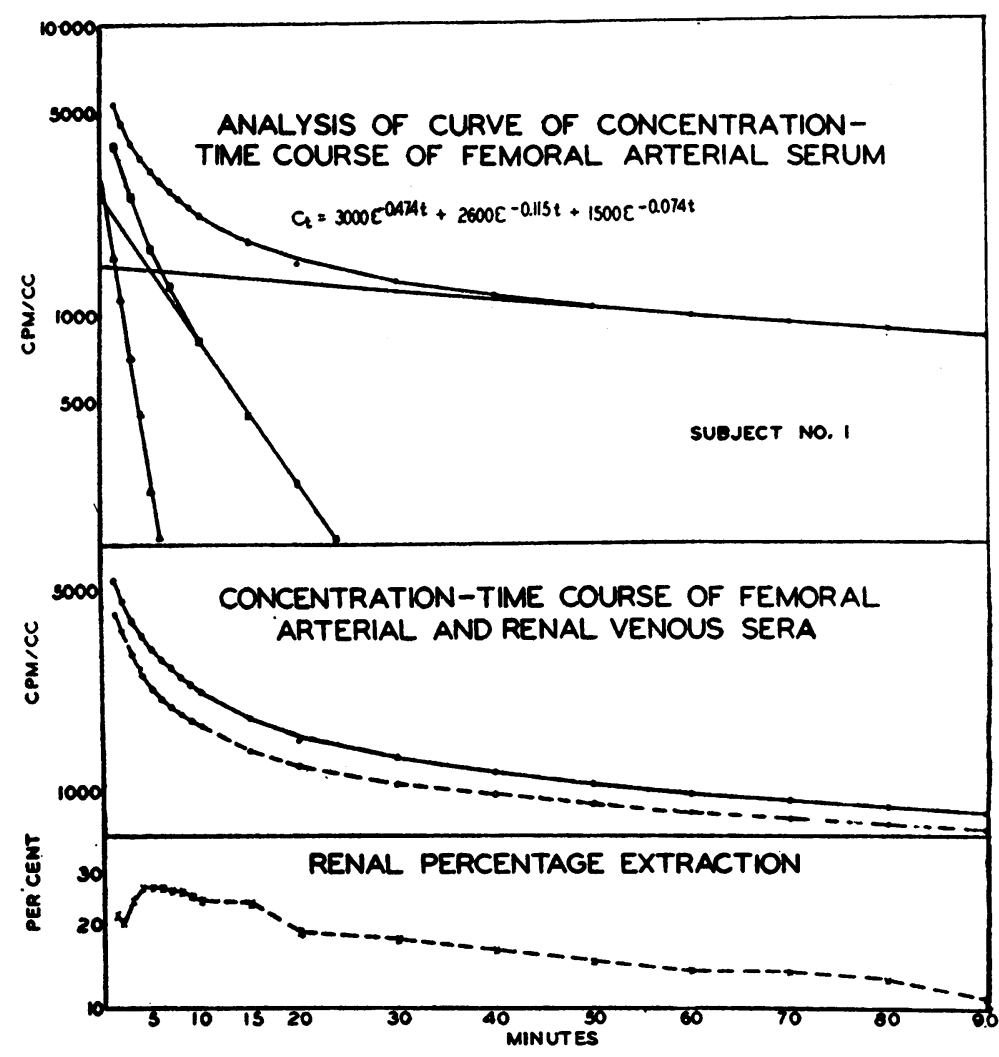

Fig. 11. Composite Graph of Analysis of Arterial Curves of Regression, Comparison of Arterial and Renal Venous Curves of Regression and Time Course of Percentage Renal Extraction of Subject No. 1 
Figure 11, the largest values for renal percentage extraction coincide with the duration of manifestation of the second most rapid regression component of the concentration-time course curve for the arterial blood. During this time also the extremital percentage arteriovenous differences were appreciable (Figure 4B). These facts indicate the importance of the kidney and other tissues in this second component of regression, which is due mainly to movement of the tracer into the tissues and relatively little to mixing of the circulating blood.

The third component of the regression curve corresponds to the period of slowly decreasing renal percentage extraction. It is due to urinary excretion of mercury and is much less concerned with mixing and movement into tissues. These data as well as much of the other data presented under "Results" lend indirect support to the concepts of the mechanisms responsible for the nature of the concentration-time curves. Obviously, the definite differences in concentration of the radiomercury of the renal, hepatic and extremital venous and femoral arterial sera cannot be accepted as conclusive evidence for inadequacy of mixing for substances which may move out of the blood stream. Certainly, differences in rate of extraction of the substance by the kidney or rate of movement of the substance into the tissues influence the results as well.

Subject No. 5 with one kidney had about onehalf the percentage extraction of radiomercury found for the other four subjects with two kidneys (Figure 4A). Furthermore, the percentage extraction by the single kidney of this subject was less for equal levels in concentration of the arterial serum entering the kidney than it was for a right kidney of any of the other four subjects (Figure 7). Therefore, the differences in percentage extraction were not due to low renal arterial concentration. The most likely cause for the low extraction for the single kidney of Subject No. 5 is impairment of function in this kidney, at least that which is concerned with extraction and excretion of mercury from the bloodstream. But it may also have been due in part to a more rapid linear rate of renal plasma flow resulting in less extraction.

The conspicuous differences between the initial concentrations (i.e., first five minutes after the injection of the tracer) of arterial and extremital venous sera (Figures 2 and 4B) are of significance in physiologic phenomena, both clinical and experimental. For instance, for a period of several minutes after a single injection of a substance it cannot be assumed that the arterial and venous concentrations are the same: This has been described and discussed for diodrast (3). Many factors are concerned with this difference, chief among which are mixing, filling of compartments, volume and rate of injection and circulation time through the extremity. The most important of these have been discussed. After the initial five minutes following injection the movement into compartments is virtually the only factor operative.

The relationship of curves of concentrationtime course of the radiomercury of arterial and hepatic venous sera to one another was different for the two subjects studied (Figure 3). In the subject with chronic congestive heart failure and extremely enlarged liver there was no constant arteriohepatic venous difference, whereas in the control subject there was. Although the evidence strongly suggests that the congestive heart failure and hepatic congestion were responsible for this difference, a definite conclusion is not justifiable on the basis of these two subjects.

The observed values of renal clearance and percentage renal extraction of radiomercury varied independently of each other (Figure 9), particularly during the early minutes of the experiments. This is due in part to a lag in appearance of urine (at the exit of the catheters) produced from a given glomerular filtrate, errors in counting of urinary samples, and temporary retention of mercury by the kidney. Such a discrepancy between urinary excretion and renal extraction is suggested by Figure 12, which illustrates the time course of the ratio of renal clearance to renal extraction fraction, $\frac{U V}{A} \cdot \frac{A-R}{A}$ (or, in other words, renal excretion to renal arteriovenous difference, $U V$ : $A-R$ ), for four subjects in whom collections of urine as well as of blood were made throughout the experiments. Since the amount of radiomercury extracted by the kidneys is represented by the product of the renal arteriovenous difference and renal plasma flow $(A-R) \times R P F$, excretion of mer- 
cury balances extraction of mercury when the value of the ratio is equal to renal plasma flow. When the value of the ratio is below renal plasma flow, the kidney is extracting more mercury than it is excreting in the urine; when the ratio is greater than renal plasma flow, the reverse is true. The low values of this ratio in all patients during the first 20 minutes and in most patients during the entire 90 minutes indicate renal retention of mercury-certainly early in all subjects and probably during the entire 90 minutes in some. Obviously, the reverse phenomenon must have existed later, although these studies were not continued long enough to demonstrate this.

An antidiuretic action of the mercurial diuretic was observed following administration of the drug in four of five patients (Figure 5). The decreased rate of volume flow occurred at a time when urinary concentration and excretion of radiomercury were increasing (Figures 5 and 6) and when the renal percentage extraction and arterial concentration of radiomercury were slowly decreasing (Figures 1 and 4A). Because of other known pharmacodynamic effects of the mercurial diuretics, it is at least reasonable to entertain the idea that the antidiuretic action may be due in part to influences which represent actions opposite to those concerned with the later-appearing diuretic one, including action on the tubules.

To estimate roughly the quantitative distribution of the mercury in compartments in the body, Figure 13 was constructed. These rough calculations have primarily qualitative significance. Plasma mercury was obtained from the product of serum concentration and plasma volume, the latter calculated according to the method of Gibson and associates (4). Renal mercury was obtained from the sums of the products of renal arteriovenous differences in concentration and renal plasma flow, the latter calculated according to the data of Smith (5). The injected mercury not accounted for in those two compartments has been labeled "tissue mercury." This latter compartment is visualized as including chiefly mercury attached to body tissues in general, i.e., muscle, liver, and skin. The shape of the curve indicating plasma mercury is identical with that of the curves of regression of the arterial blood serum.

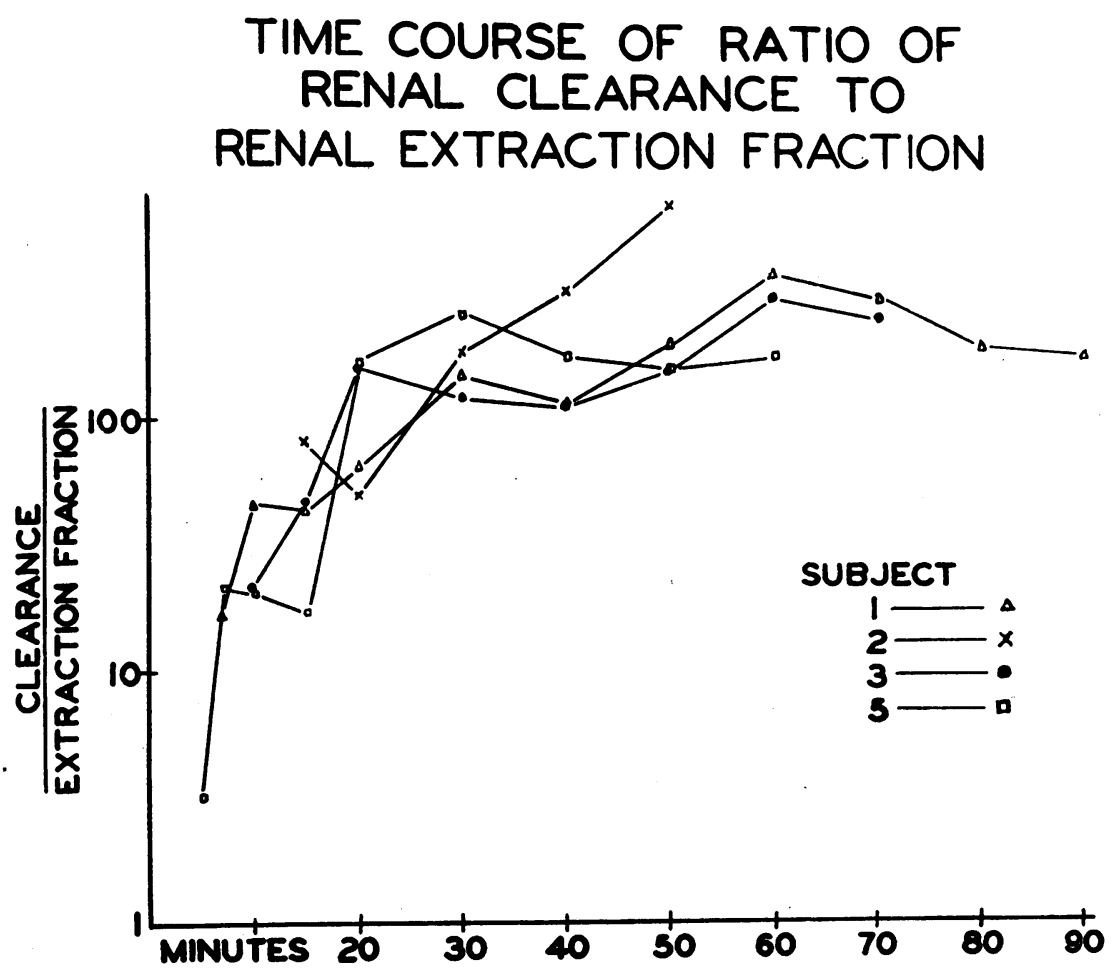

Fig. 12. Variation with Time of the Ratio of Renal Clearance of Radiomercury to Renal Extraction Fraction of Radiomercury 


\section{TIME COURSE OF DISTRIBUTION OF RADIOMERCURY IN SUBJECT NO. 3}

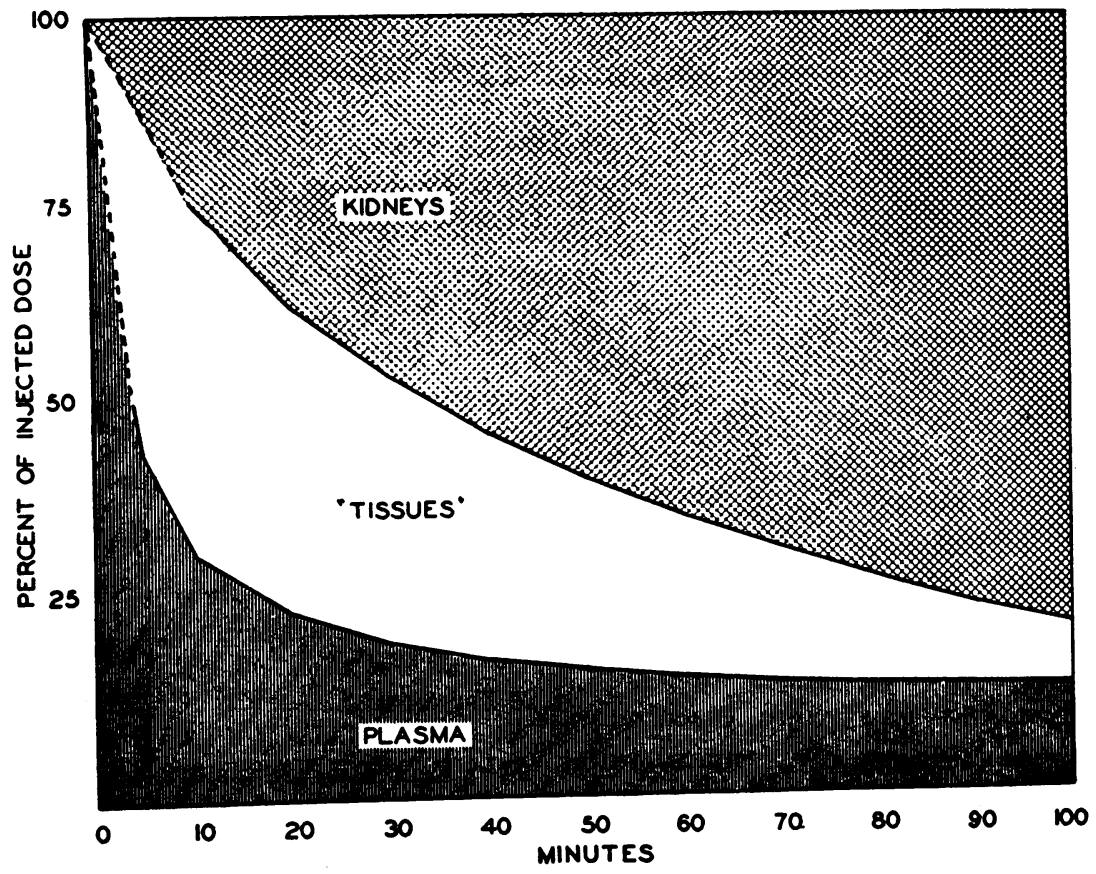

Fig. 13. Time Course of the Distribution of Radiomgrcury in "Compartments"

Value obtained as described in the text.

It is striking, however, that over 50 per cent of the injected mercury has been lost from the serum within five minutes after injection. The cumulative maximum effects of all the limitations mentioned will not account for more than a fraction of this loss as mercury retained within or excreted by the kidneys. This is proof, therefore, that the large extremital $\mathrm{A}-\mathrm{V}$ differences observed early are not due to mixing alone but are the resultant of mixing plus rapid movement into mercurial spaces. It is interesting that the "tissue mercury" compartment reaches its maximum size between 10 and 20 minutes; this is the same period of time required for extremital arterial and venous concentrations of mercury to become essentially the same, i.e., after 10 to 20 minutes, no more mercury is being "extracted" by the tissues of the extremities. If, for the period after 20 minutes, a theoretic arterial curve of regression was calculated from the amount of mercury being removed by the kidneys, it is seen that its rate of regression would be much more rapid than that which was observed. This indicates that mercury is being returned to the circulating plasma from some source, the obvious source being depots where mercury was loosely-bound immediately after the injection and when the plasma concentrations were highest, i.e., "tissue mercury."

Because of the small number of subjects studied, the significance of differences, or their absence, in renal phenomena concerned with mercury between the normal subjects and the patients with congestive heart failure cannot be considered to be characteristic of failure in general. The same is true for the hepatic phenomena recorded.

The many interesting points noted in the results will not be discussed here. Figure 10 is presented to permit a more successful correlation of these various physiologic phenomena which were under simultaneous observation. It is possible from this illustration to correlate several of the observations of the tracer as it migrates through the body, particularly in the blood and urine. 


\section{SUM MARY}

By use of venous catheterization and a mercurial diuretic containing a radioactive isotope of mercury, it has been possible to measure and compare the time course of the mercury of the diuretic in renal or hepatic venous blood, extremital venous blood, arterial blood, and urine. From these figures was calculated the percentage extraction of mercury by kidney, extremity and liver. In five subjects, renal extraction varied from 5 to 25 per cent between 10 and 90 minutes after injection of the diuretic. In a control subject, hepatic extraction varied from 5 to 10 per cent during this period but no hepatic extraction was detected in a subject with congestive heart failure. Concentration of radiomercury in extremital venous blood was lower than in arterial blood until 10 to 20 minutes after injection, after which the two concentrations were essentially the same. A temporary decrease in urinary rate of volume flow was found to precede the usual mercurial diuresis. This decreased rate of flow coincided with the appearance of mercury in extremely high concentrations in the urine. This reciprocal relationship of rate of urinary flow to urinary concentration of radiomercury tended to maintain the urinary rate of excretion of mercury at a fairly uniform level. Functional patterns for the two kidneys of the same subject were similar to one another. After stabilization, renal clearances of radiomercury varied from 10 to 60 cc. per minute. The number of patients studied was too small to permit conclusions regarding differences in renal or hepatic handling of mercury by cardiac and control subjects.

These studies were subject to several limitations resulting from: (1) the time required for circulation through the organ being studied; (2) the lag in time of appearance of urine at the exit of the urinary catheter after glomerular filtration; (3) the possible variations in renal plasma flow; and (4) incomplete mixing of the tracer in the blood during early periods of the study. The significance of the observations and the limitations is discussed.

\section{BIBLIOGRAPHY}

1. Cournand, A., and Ranges, H. A., Catheterization of the right auricle in man. Proc. Soc. Exper. Biol. \& Med., 1941, 46, 462.

2. Threefoot, S. A., Ray, C. T., Burch, G. E., Cronvich, J. A., Milnor, J. P., Overman, W., and Gordon, W., Concentration-time course in the plasma of man of radiomercury introduced as a mercurial diuretic. J. Clin. Invest., 1949, 28, 661.

3. Brun, C., Hilden, T., and Raaschou, F., The significance of the difference in systemic arterial and venous plasma concentrations in renal clearance methods. J. Clin. Invest., 1949, 28, 144.

4. Gibson, J. G., 2nd, Peacock, W. C., Seligman, A. M., and Sack, T., Circulating red cell volume measured simultaneously by the radioactive iron and dye methods. J. Clin. Invest., 1946, 25, 838.

5. Smith, H. W., Lectures on the Kidney. University Extension Division, University of Kansas, Lawrence, Kansas, 1943. 